\title{
How Does Extended Reality Influence Consumer Decision Making? The Empirical Evidence from A Laboratory Experiment
}

\author{
Nannan Xi \\ University of Vaasa \\ \& Tampere University \\ nannan.xi@tuni.fi
}

\author{
Elpida Bampouni \\ Gamification Group \\ Tampere University \\ elpida.bampouni@tuni.fi
}

\author{
Juho Hamari \\ Gamification Group \\ Tampere University \\ juho.hamari@tuni.fi
}

\begin{abstract}
Extended reality (XR) technologies such as virtual reality (VR) and augmented reality (AR) have been postulated to revolutionize many human endeavors commonly undertaken at a location such as work, education, shopping and so on. While this future scenario may become reality sooner or later in the future, it is an increasingly pertinent question how these technologies may affect our cognitive processing and related decision making. Especially in business and marketing, consumers' decision making and choice plays the determining role in the business success. Therefore in this study we conduct a laboratory experiment in the shopping context for investigating the two main aspects of consumer decision making (quality and satisfaction) in four different extended reality conditions; physical reality, augmented reality, virtual reality and augmented virtuality $(N=160)$. The results show that $X R$ technologies differentially influence consumer decision making. More specifically, AR had no significant effect on decision quality or satisfaction; while VR was positively associated with decision quality. In addition, there was no significant interaction effect between $A R$ and VR on decision making.
\end{abstract}

\section{Introduction}

Extended reality (XR) technologies, including virtual reality (VR) and augmented reality (AR), have been touted to introduce information richness into (digital) shopping, and therefore, has been receiving increasing attention from business practitioners and scholars. AR superimposes the 'augmenting' content related to e.g. products, brands and services over the reality which enables customers to efficiently obtain and interact with extra information presented through several modalities [1]; while VR allows consumers to immerse themselves in a digitalized environment that may enable experientality, playfulness and nonconsequentiality to shopping behavior [2]. Given decision making is what makes the human element alive and functional [3], there is a fundamental question - when transitioning from 'reality' to 'virtuality', will the decision making differ? However, beyond optimistic expectations, empirical research on the effect of XR on decision making is still scarce [4][5]. At the same time, the experiences of using XR applications have not redeemed the high hopes set for it. Quite a few XR applications have become to be regarded as either 'gimmicks' for attracting new consumers or simply as supplements to traditional marketing techniques and business models. All these seem to come from the concerns on the role of XR in business performance. Marketers and practitioners hardly know whether and how XR technologies have different impacts on consumer decision making regarding choice and purchase of products and services.

Thus, to fill out the research gap, in this study we designed a 2 (VR: with vs. without) by 2 (AR: with vs. without) between-subject experiment in a shopping context to investigate how different XR technologies influence the different aspects of consumers' decision making among 160 university students. To be more specific, consumer decision making is evaluated by decision quality and decision satisfaction regarding a shopping task related to using a 10 euros gift card within 10 minutes. A physical store (as the control) was built on the university campus and three different XR stores were constructed accordingly (see Figure 1 in section 3). Based on the findings, this study provides a considerable research contribution to the interdisciplinary field of information systems, humancomputer interaction and marketing management as well as valuable guidance to XR designers, developers and business practitioners. 


\section{Background}

\subsection{Extended reality}

$\mathrm{XR}$ technologies, mainly including $\mathrm{AR}$ and VR have been rapidly evolving and making a noticeable presence in business fields, including advertising [6], tourism [7], marketing [8], and retail [1][[9]. VR refers to technologies that aim at immersing individuals in another simulated artificial environment [10][2]. Generally, the current VR displays can be classified in three categories based on their immersiveness [11][12], regarding how much they span the field-of-view of the user and consequently also block 'the real' reality: fully immersive (e.g. headset), semi-immersive (e.g. cave automatic virtual environments), and low or nonimmersive displays (e.g. desktop-based). Due to this variety in the use of the term, to some extent VR has been inconsistent in the existing literature (see e.g. [13][14][15][16]). One of the main characteristics of VR is related to (tele)presence. It is a psychological effect [17][12] which refers to a user's consciousness being transferred to a different environment compared to the one they are actually in. It creates a subjective experience of 'being there' and it is highly associated with factors such as immersion and interactivity [17][10]. Based on the systematic literature review among 72 articles related to VR commerce, Xi \& Hamari proposed a definition from a broader perspective in which VR represents the technologies substituting the perceived reality [2].

On the other hand, AR allows users to perceive their environments and additional digital information simultaneously [18]. This form of reality augmentation provides an opportunity for real-time interactions which incorporate an overlay of virtual elements, such as 3D models, text, images, sounds, and videos [19][20][18]. As a result, the key characteristics of AR usually comprise of digital enhancements, computergenerated information, and interactions [20]. There is a large variety of AR compatible devices (mainly for visual experience), including specialized glasses, headsets and the majority of smartphones. One of the common uses of AR in business is permitting users to virtually try-before-you-buy experiences (e.g. clothing, cosmetics, and furniture), which makes product understanding and visualization easier [20][21]. Notably, augmented virtuality (AV) can also be encountered although less frequently. AV takes place in virtual environments and displays additional augmented elements, resulting in an experience of VR and AR simultaneously [22][23].

\subsection{Decision making experience}

Decision making is an integral part of modern life with individuals making a daily impact on personal, societal, economic, environmental and countless other matters [24], and refers to the process of making a choice or selecting a course of action among various alternative options [25]. Decision making is a complex cognitive process influenced and mediated by numerous factors such as individual motives, mental representations, attentional resources, working memory, strategic thinking and reasoning skills [24][25]. One of the areas that decision making plays a fundamental role regards consumer behavior in business activities [26].

Consumer decision making focuses on purchase behaviors, customer selection strategies, prior knowledge effects, mental categorization influences and more [27]. Consumer decision making can lead to mutual benefits for both customers and service or product providers. For example, it can help providers improve their marketing approach in order to be more effective towards consumers [26]. There have been multiple theoretical models describing consumer decision making, such as the Engel, Kollat \& Blackwell model, Simon's model, Keeney's four-stage decision making model, and McKinsey's dynamic model [26][13]. Although most models demonstrate a level of resemblance to the traditional five-stage model which includes, the consumer's need recognition, information searching and evaluation of options, the purchase and the post-purchase stage [26][13]. A few of the main reported factors notably impacting a consumer decision making process include the number of alternative options and the number of variable attributes one has to consider [27]. The higher the amount, the more challenging and complex a decision making task becomes [27][28].

In literature, it can be seen that there are many approaches to evaluate decision making experience. One way to accurately measure decision making experience is the assessment of decision making performance/quality, which could provide a relatively objective indicator of one's judgment. Decision makers are usually requested to make an optimal choice among different alternatives. Since human decisions are not always rational or optimal, there are several approaches developed aiming to improve their way of thinking, which are often tested with similar choice formats [29][30]. Decision tasks have been used as a way to examine an individual's rational ability to distinguish the optimal course of action compared to other available options. Several studies have focused their research directly on the various aspects of such choosing tasks, such as the way alternative choices are presented [31], and effects of uncertainty [32]. As a 
result, decision making quality can be measured by a choices' consistency with rationality [33][34]. Another way to evaluate decision making experience is decision satisfaction which is associated with the consumers' subjective feelings and perceptions. Consumer satisfaction has been a central topic for consumer behavioral research and is positively associated with purchases and customer loyalty [33][36][37]. Heitmann emphasized the significance of providing a pleasant decision process to consumers and suggested that although different, the way consumers experience their decision making process, influences the overall consumer satisfaction [30]. As a result, the perception of decision satisfaction plays an integral role in ensuring further consumer satisfaction.

\subsection{XR and consumer decision making}

XR plays an important role in decision making and satisfaction. Business environments have been frequently recruited in several studies, indicating XR's influences on decision making (see e.g. [15][38][39] where $\mathrm{XR}$ is used in selecting clothing, furniture and even mueslis). Based on the cognitive theories for information processing, Fan et al. (2020)[20] suggest that the adoption of AR may positively influence consumers' cognitive fluency and decrease cognitive load, thus leading to more positive product attitudes. Similarly, VR appears to provide users a greater understanding of products as well as helping them decrease sought information, consequently shortening the decision making process [40].

Knowing how and why consumers behave in a certain way in consumption decision making helps companies improve their marketing strategies and be more successful [28]. However, findings may be potentially influenced by several factors. To begin with, informativeness has been identified as a driving force to decision making [41]. Nevertheless, some studies may provide additional information in the XRmediated conditions, and thus causality effects are hard to examine, see e.g. [42][43]. For example, studies investigating the effects of AR with try-before-you-buy applications compared to traditional online websites, unsurprisingly demonstrated higher satisfaction and purchase intention [20][42]. Furthermore, findings for $\mathrm{VR}$ and AR are often discussed and used as a reference to one another for hypothesizing and discussing expected outcomes. However, there are only few studies comparing these two main XR technologies to each other directly [9], and findings have often been conflicting (e.g. [9] discusses findings of both AR and VR while [15][20][42] show distinct results regarding XR consumer behavior). Finally, some findings are incomparable due to the lack of controls or the difference in the research approach. Such issues along with the fact there are not many studies researching decision making performance and satisfaction make it hard to accurately pin-point and understand the effects of XR on decision making.

Therefore, the research goal in this paper is to address these issues and aforementioned knowledge gaps in the current XR-related research. Our aim is to answer two research questions which formulate as follows: 1) How do XRs influence consumer decision making performance, and 2) How do XRs influence consumer decision satisfaction?

\section{Research method}

In this study, a 2 (VR: with vs. without) by 2 (AR: with vs. without) between-subject experiment was designed to investigate how XR would influence consumer decision experience. In total four shopping environments (second-hand music shops) were constructed that all allow participants to conduct a series of shopping behaviors including information searching, processing, freely moving, and interacting with products and the environment. Each participant was randomly assigned to one of the four shopping conditions and asked to make his/her own purchase decision after the 10-minute shopping experience. The study design and procedure adhered to the National Advisory Board's ethical guidelines on Research Ethics of Finland.

\subsection{Materials}

A physical shop $\left(4.24 \times 5.09 \mathrm{~m}^{2}\right)$ was built onto the university campus. The other three XR-mediated shops were designed based on the physical shop (see Figure 1 below). The second-hand LP records were selected as the ideal product stimuli to control the external influence of prior product knowledge and preference on decision making. In addition, there is no gender bias towards music products. To maximize the realistic shopping experience, approximately 600 LP record products were used. The price of the products ranged from 3 euros, 6 euros to 9 euros (each product had the price tag on the back). Additionally, the extra important product information was gathered from the website Discogs and provided to participants. The general information, tracklist, statistics, companies, and credits information were selected by the researchers.

For Group 1 (without AR, without VR), the shop functioned as a common bricks-and-mortar shop (nonXR shop). Product information was printed and attached to the physical shelves. 
For Group 2 (with AR, without VR), the shop functioned similarly but with the exception of product information being displayed through AR headset display-Microsoft HoloLens. The (digital) product information only 'showed up' whenever the participant was looking directly at the same LP record (front cover).

For Group 3 (without AR, with VR), the same room was used; however, the 'control' condition was fully replicated by employing laser scanning (LiDAR) to acquire a point-cloud map of the space-based on which a 1-on-1 scale $3 \mathrm{D}$ model of the shop was built in
Unity. The front and back covers of the LP records were scanned in high quality and added as textures on the sides of plane 3D objects. The participants used the Valve Index headset and its controllers.

For Group 4 (with AR, with VR), it combined the condition in Group 3 with the overlaid product information as in the condition of AR Group. The product information was displayed as a superimposed floating information box appearing next to the product the participant was looking at based on head tracking.

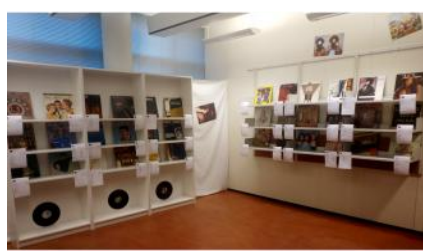

Group $1(\mathrm{AR}=0, \mathrm{VR}=0)$

Note: $0=$ without, $1=$ with

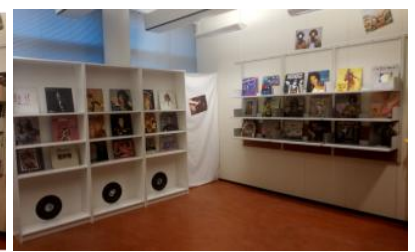

Group $2(A R=1, V R=0)$

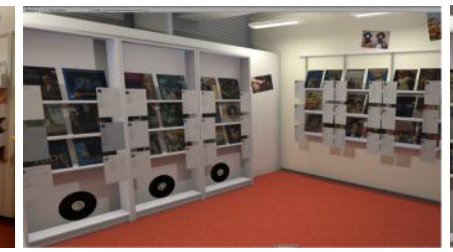

Group $3(\mathrm{AR}=0, \mathrm{VR}=1)$

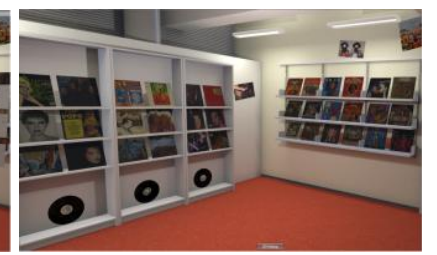

Group $4(\mathrm{AR}=1, \mathrm{VR}=1)$

Figure 1. The shop design in the experiment

\subsection{Participants}

In the fall semester of 2019 , a total of 165 student participants were recruited from Tampere University (Finland) to participate in the experiment. 3 participants were disqualified and 2 participants were further dropped in data analysis due to no purchase decision being made. Thus, the sample size was 160 (Group 1: $n=40$; Group 2: $n=41$; Group 3, $n=40$; Group 4: $n=39$ ). Among all participants, 47.5\% were female, $55.6 \%$ were between $20-24$ years old, $57.5 \%$ were bachelor students, and $36.3 \%$ were master students. Over $66 \%$ reported music is important (including extremely important).

\subsection{Measures}

In this study, the decision making experience was evaluated based on both 'objective' and 'subjective' decision-related constructs. On one hand, according to the traditional consumer choice theories, individuals evaluate each alternative in terms of the utility and then select the alternative yielding maximum utility (rational decision, see [44]). On the other hand, making a satisfactory decision usually involves a series of cognitive and affective processes and depends on factors such as the availability of options and the alignability of an assortment [30]. The former is related to decision performance such as quality and can be considered as the 'objective' decision making

experience; the latter is more like a 'subjective' decision making experience.

Decision quality was measured by the amount of money spent and the number of products bought. Given the shopping task was to use the 10 euros gift card in the second-hand record shop, there are in total six kinds of purchase decisions in the choice set purchasing only 1 product with money spent 3/6/9 euros, 2 products with money spent $6 / 9$ euros, and 3 products with money spent 9 euros. The optimal decision is considered as purchasing the most products possible within maximum gift card value. For example, the highest quality decision should be to spend the maximum value of the gift card (9 euros) and buy the maximum amount of products (3 products).

Decision satisfaction was measured by three items, which were adapted from [30], from 1 strongly disagree to 7 strongly agree: $D S 1$-I found the process of deciding which product(s) to buy frustrating (reversed item); DS2-I found the process of deciding which product(s) to buy interesting; DS3-I was satisfied with my experience of deciding which product option(s) to choose. The Cronbach's $\alpha$ value of decision satisfaction was 0.573 which demonstrated an acceptable inter item consistency [45].

\subsection{Procedures}

Each participant was randomized to join one of the four groups. Before starting the shopping task, researchers first introduced the entire experiment procedure and guided participants to understand the 
consent form of the study. Researchers provided extra tutorials for participants in the three XR-mediated shopping groups, including how to wear the headset, control objects, navigate in virtual reality and read information. Each participant was also told that if he/she needs any help or feels uncomfortable during shopping, a short break during the experiment can be offered. A scenario was designed as follows:

While you are passing by a second-hand LP record shop, you suddenly realize that you have a 10 euro gift card given by your friend last week. You find out that the expiry date of the gift card is today, which means you have to use it as soon as possible. Thus, you decide to use this gift card to get records for yourself before the shop closes. Remember the shop will close in 10 minutes.

Participants were asked to make the purchase decision independently in accordance with their own preferences. One researcher acted as the 'cashier'.
When the shopping time was out, the 'cashier' counted the price of each product on the check-out table and asked participants to pay with the given gift card.

\section{Results}

\subsection{Descriptive result}

Table 1 presents the descriptive information related to decision quality and decision satisfaction among each group. In this study, the decision quality was measured by the number of products bought and the amount of money spent. It can be seen that generally less than 2 products were bought and money spent was no more than 9 euros in all of the conditions. In addition, the highest decision quality was in Group 4 $(M=2.41)$ and lowest in Group $2(M=2.20)$; while in terms of decision satisfaction, the highest was in Group $1(M=5.65)$ and the lowest was in Group $4(M=5.32)$.

Table 1. Descriptive statistics of decision quality and satisfaction in each group

\begin{tabular}{lccccccccc}
\hline \multirow{2}{*}{ Group } & $\boldsymbol{n}$ & \multicolumn{2}{c}{ Products bought } & \multicolumn{2}{c}{ Money spent } & \multicolumn{2}{c}{ Decision quality } & \multicolumn{2}{c}{ Decision satisfaction } \\
\cline { 2 - 9 } & & $M$ & $S D$ & $M$ & $S D$ & $M$ & $S D$ & \multicolumn{2}{c}{ M } \\
\hline 1 & 40 & 1.70 & 0.56 & 8.63 & 1.01 & 2.29 & 0.34 & 5.65 & 0.82 \\
2 & 41 & 1.51 & 0.60 & 8.63 & 0.99 & 2.20 & 0.39 & 5.33 & 0.95 \\
3 & 40 & 1.83 & 0.64 & 8.93 & 0.47 & 2.40 & 0.34 & 5.33 & 0.91 \\
4 & 39 & 1.90 & 0.60 & 8.80 & 0.81 & 2.41 & 0.36 & 5.32 & 1.06 \\
\hline
\end{tabular}

Note: The values of money spent were recoded as 3 euros - 1, 6 euros - 2, 9 euros - 3 .

\subsection{Two-way ANOVAs}

In order to examine the relationships between AR and VR on consumers' decision making quality and satisfaction, a series of between-subjects two-way analysis of variance (ANOVA) was adopted. Prior to conducting ANOVAs, the homogeneity of variance assumption was tested. Given the two Levene's $F$ tests were statistically insignificant ( $p$-values $>.05)$, homogeneity of variance was not violated. The results of ANOVAs for decision quality and satisfaction are presented in Table 2 and Figure 2.
Surprisingly, AR had no significant effect on decision quality, $F(1,156)=0.528, p=.469$ or decision satisfaction, $F(1,156)=1.266, p=.262$. VR had a positive effect on decision quality, $F(1,156)=$ $8.404, p=.004$ but no effect on decision satisfaction, $F(1,156)=1.269, p=.262$. Participants in conditions with VR $(M=2.405, S D=0.040)$ had higher decision quality than those in non-VR conditions $(M=2.241$, $S D=0.040)$. VR explained $5.1 \%$ of the variance in decision quality. The results also show there was no significant interaction effect between AR and VR on consumer decision making ( $p$-values $>.05)$.

Table 2. Results of two-way ANOVAs

\begin{tabular}{|c|c|c|c|c|c|c|c|c|c|c|c|}
\hline \multirow[b]{2}{*}{ Variables } & \multicolumn{2}{|l|}{ Levene's } & \multicolumn{3}{|l|}{ AR } & \multicolumn{3}{|l|}{ VR } & \multicolumn{3}{|l|}{ AR×VR } \\
\hline & $F(3,156)$ & $p$ & $F(1,156)$ & $p$ & $\begin{array}{l}\text { Partial } \\
\eta^{2}\end{array}$ & $F(1,156)$ & $p$ & $\begin{array}{l}\text { Partial } \\
\eta^{2}\end{array}$ & $F(1,156)$ & $p$ & $\begin{array}{l}\text { Partial } \\
\eta^{2}\end{array}$ \\
\hline $\begin{array}{l}\text { Decision } \\
\text { quality }\end{array}$ & 1.019 & .386 & 0.528 & .469 & .003 & 8.404 & .004 & .051 & .825 & .365 & .005 \\
\hline $\begin{array}{l}\text { Decision } \\
\text { satisfaction }\end{array}$ & 1.520 & .211 & 1.266 & .262 & .008 & 1.269 & .262 & .008 & 1.136 & .288 & .007 \\
\hline
\end{tabular}



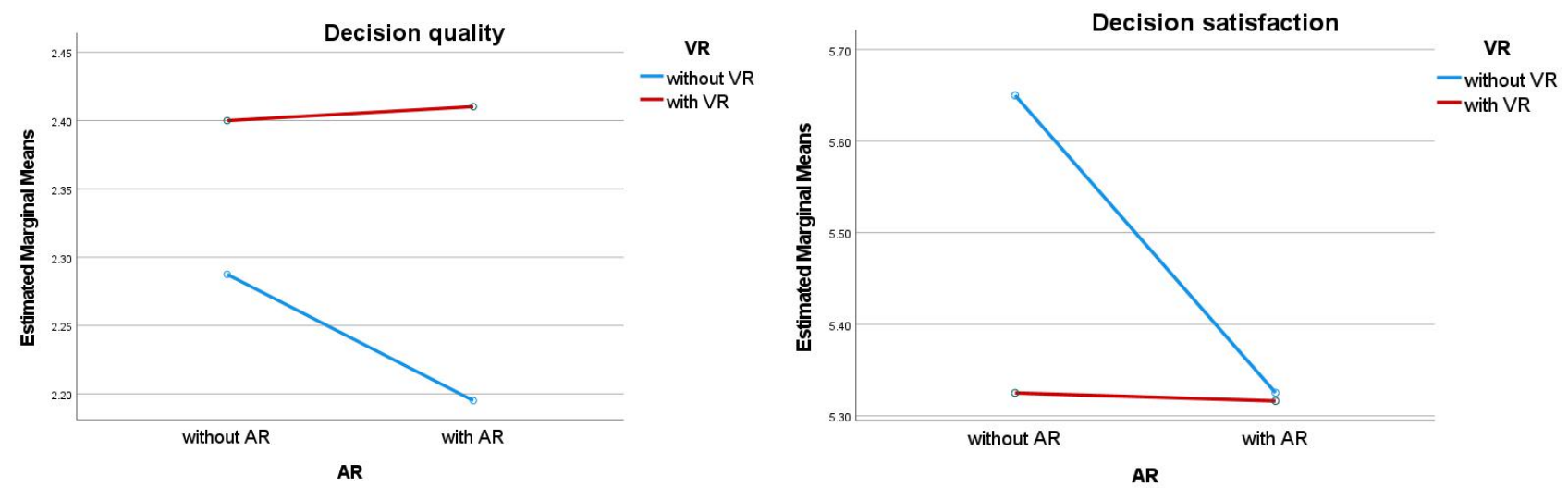

Figure 2. Profile plots of decision quality (left) and decision satisfaction (right)

\section{Discussion}

According to the results, it can be seen that AR had no significant negative or positive effect on consumer decision making experience. Even though AR might be associated with cognitive load [46][47], such negative effect of AR on cognitive function seems not to be associated with decision quality and satisfaction. While there is such a possibility that the relationships between $\mathrm{AR}$ and decision quality and decision satisfaction might be (fully) mediated by other "unmeasured" variables. Consumer decision making usually involves a lot of cognitive activities including e.g. information searching, processing, evaluating and selecting process as well as being influenced by emotion-related and personal factors. Thus, AR might be associated with these unknown factors and further influence decision quality and satisfaction, which requires further investigation in future studies. The other possible explanation for the insignificant effects is that in this study the nature of AR was considered as the technology of presenting digitalized product information. To ensure the rigor of laboratory experiments, the extra content and vivid interactions were excluded for strictly controlling the influences of external factors on decision making (e.g. the amount and types of information were controlled to be approximately the same), which might lead to the different results from other studies.

Interestingly, VR had a significant positive effect on decision quality. The results indicate consumers seem to make more optimal decisions in environments constructed by virtual reality. One potential reason might be related to the less time pressure led by nonconsequentiality of VR [2]. When conducting shopping activities in virtual reality, participants tend to have fewer concerns and less psychological pressure about the consequences involved. Thus, for the 10-minutes shopping task, the perception of time-consuming in the VR environment might be weaker than in the non-VR environment. This could be linked to the fact that consumers are more likely to make rational decisions under lower time pressure [48][49][50]. On the other hand, given that most participants were not familiar with VR shopping compared to daily shopping in the real world; they might have been especially focused and made more effort on completing the shopping task in the new and unknown environment. Accordingly, the performance of completing the shopping task in VR conditions (Group 3 and 4) might become higher than non-VR (Group 1 and 2).

In addition, VR had no significant effect on decision satisfaction. In other words, participants experienced a similar level of satisfaction towards making purchase decisions in VR as in the non-VR environment. It should be noted that in literature quite a few studies have provided empirical evidence that users usually experience high satisfaction in virtual reality, see e.g. [51][52]; our results seem to be inconsistent with such previous findings. One possible explanation might be that the laboratory experimentbased study controlled as many external factors (e.g. extra information, vivid content and interesting interaction) as possible to increase the internal validity. To investigate the essence of VR and understand the core differences between VR and non-VR conditions, in this study the real shopping environment was closely duplicated in the virtual reality without adding extra information, interesting content and other interactive affordances. Therefore, when VR is considered as the technology for substituting the perceived reality such as the physical store in this study, consumers might feel easy as they conduct shopping activities in the real world and be satisfied with the overall decision making process [15]. 


\subsection{Research contribution}

First, this study enriches the current research of XR shopping, which is one of the most important emerging research directions in technology-mediated digital marketing. According to the systematic literature review conducted by [2] and [1], the majority of studies related to VR shopping and AR shopping have mainly focused on consumers' psychological reactions and responses towards XR shopping. By investigating how AR and VR differently influence consumers' decision quality and satisfaction, this study shows that only VR would have a significant effect on decision quality, and neither of the two main XR technologies could significantly influence decision satisfaction. Thus, the findings address the research questions on the role of $\mathrm{XR}$, as the information technology, in decision making satisfaction and decision quality in the shopping context. This makes a considerable research contribution in the interdisciplinary field of information systems and marketing science, as well as providing new knowledge to cognitive and decision making theories.

In addition, in the majority of XR-related studies, $\mathrm{AR}$ and VR as the core concepts of XR have been investigated separately and rarely directly compared; and sometimes considered as interchangeable terms. In this study, AR has been considered as the technology for modifying realities while VR as technologies for substituting realities. Based on the rigorous laboratory experiment design, this study provides empirical evidence on the difference between the two XR technologies and it provides guidance to future research design regarding the comparison of different XR technologies.

\subsection{Practical implication}

Given the study was conducted in the shopping environment and the experiment task was directly related to consumer choice and purchase decision, retail practitioners and managers can directly benefit from these research findings. For example, the use of augmenting content and information related to products, brands, stores and service in both physical and virtual environments would not increase or decrease decision quality and satisfaction. On the other hand, consumers are more likely to make rational decisions in virtual reality - maximize utility. Thus, retailers should carefully consider the product quantity, pricing strategy and product type. For example, consumers may become more sensitive to product promotions and discounts, and have higher preference for utilitarian consumption.
Additionally, the results can also provide practical guidance for XR designers and developers in business as well as other fields. For example, more direct and useful information should be considered to be included in VR-mediated advertising, product presentations and marketing activities given VR might be positively related to consumers' rational behaviors; while the digitalized information via AR could improve the convenience of consumers to access information with relatively low economic cost (e.g. mobile-based AR), as well as lead to a similar level of decision making experience. Further, VR can be considered as an effective tool for improving individual decisions and cognitive skills. Thus, relatively more complicated cognitive tasks and training can be designed and conducted in virtual reality for studies in cognitive psychology, education and healthcare.

\section{Limitations}

This study makes a considerable contribution to the interdisciplinary field of information science, marketing management and cognitive psychology by investigating how $\mathrm{XR}$ influences decision making experience; however, the consumers' decision making process in $\mathrm{XR}$ is still unclear. This study provides empirical evidence on the effects of XR on the decision outcomes (quality and satisfaction) rather than revealing the in-depth mechanism of the decision process. Therefore, future researchers are encouraged to investigate research questions related to decision making processes such as information-seeking behaviors, establishment of criterias, development and assessment of alternatives, and decision actions in extended realities.

In order to evaluate the decision quality, this study measured the economic value of using a gift card for purchasing products (the amount of money spent, and the number of products bought by each participant) rather than hedonic and emotional benefits. Undeniably, individual preferences, product knowledge and emotional bonds have impacts on the product choices in any consumption context. We note the limitation that even though the second-hand record products were selected and randomized into the four conditions; such factors might still influence the decision quality. A more granular analysis of the purchasing reasons can be conducted in the future study.

In addition, in this study, we did not examine the boundary conditions of consumer decision making in XR. Factors such as age, gender, income, education, culture, personality, acceptance of technology, immersive tendency, time pressure might play important moderating roles between the relationships of XR and decision making experience. Therefore, 
future studies can conduct a more granular analysis on these moderating effects in XR-enabled decision management. In addition, cross-cultural factors may play important roles in consumer decision making. Future research could take cultural differences into consideration and conduct cross-cultural comparative studies.

Another limitation of this study is that only student samples were selected and the maximum consumption amount was limited to 10 euros. Even though students are one of the main consumer groups of music products, the purchasing power of students is limited. We would encourage future studies to consider recruitment of regular shoppers and design more complicated shopping tasks for further investigations.

Last but not least, the shopping experience in the VR-mediated shopping conditions (Group 3 and Group 4) was limited to visual experience. Thus, compared with Group 1 and Group 2, participants might not obtain a full shopping experience with multiple senses such as sound, touch and smell. Future studies could investigate the influence of multisensory experiences brought by XR technologies on decision making.

\section{Acknowledgement}

This work was supported by KAUTE Foundation under Grant No. 20190003 and No. 20200531; OP Ryhmän Tutkimussäätiö under Grant No. 20200040; Liikesivistysrahasto under Grant No. 14-7798; Grant No. 4708/31/2019; and Academy of Finland under Grant No. 327241 and Grant No. 337653. This work was carried out with the support of Centre for Immersive Visual Technologies (CIVIT) research infrastructure in Tampere University, Finland. Special thanks to Juan Chen, Filipe Gama, Henry Korkeila, Henrietta Jylhä, Shuo Yang's contribution to the XR environment development, experiment design and implementation. The authors would also like to thank all student participants from Tampere University, Finland.

\section{References}

[1]M. Riar, J. J. Korbel, N. Xi, R. Zarnekow and J. Hamari, "The use of augmented reality in retail: A review of literature", Proceedings of the 54th Hawaii International Conference on System Sciences, 2021, pp. 638-647.

[2]N. Xi and J. Hamari, "Shopping in virtual reality: A literature review and future agenda", Journal of Business Research, 134, 2021, pp. 37-58.

[3]F. C. Uzonwanne, "Rational Model of Decision Making. In: Farazmand A. (eds) Global Encyclopedia of Public Administration, Public Policy, and Governance. Springer, Cham, 2016.

[4]E. Pantano, A. Rese, and D. Baier, "Enhancing the online decision-making process by using augmented reality: A two country comparison of youth markets", Journal of Retailing and Consumer Services, 38, 2017, pp. 81-95.

[5]H. Qin, D. A. Peak, and V. Prybutok, "A virtual market in your pocket: How does mobile augmented reality (MAR) influence consumer decision making?", Journal of Retailing and Consumer Services, 58, 2021, no. 102337.

[6]J. Sung and K. Cho, "User Experiences with Augmented Reality Advertising Applications: Focusing on Perceived Values and Telepresence Based on the Experiential Learning Theory”, In: Park J., Jin Q., Sang-soo Yeo M., Hu B. (eds) Human Centric Technology and Service in Smart Space, Lecture Notes in Electrical Engineering, 182, Springer, Dordrecht, 2012.

[7]R. Yung and C. Khoo-Lattimore, "New realities: a systematic literature review on virtual reality and augmented reality in tourism research", Current Issues in Tourism, 2019.

[8]M. Wedel, E. Bigné and J. Zhang, "Virtual and augmented reality: Advancing research in consumer marketing", International Journal of Research in Marketing 37, 2020, pp.443-465.

[9]F. Bonetti, G.Warnaby and L. Quinn, "Augmented Reality and Virtual Reality in Physical and Online Retailing: A Review, Synthesis and Research Agenda", In: Jung T., tom Dieck M. (eds) Augmented Reality and Virtual Reality. Progress in IS. Springer, Cham, 2018.

[10]J. Steuer, "Defining virtual reality: dimensions determining telepresence", Journal of Communication, 42(4), 1992, pp.73-93.

[11]P. Cipresso, I. Giglioli, M. A. Raya and G. Riva, "The past, present, and future of virtual and augmented Reality research: A network and cluster analysis of the literature", Frontiers in Psychology, 9, 2018.

[12]M. Gutierrez, F. Vexo and D. Thalmann, Stepping into virtual reality. London, UK: Springer-Verlag, 2008.

[13]D.Sihi, "Home sweet virtual home: The use of virtual and augmented reality technologies in high involvement purchase decisions", Journal of Research in Interactive Marketing, 12 (4), 2018, pp.398-417.

[14]M. R. Wilson, J. S. McGrath, S. J. Vine, J. Brewer, D. Defriend and R. S Masters, "Perceptual impairment and psychomotor control in virtual laparoscopic surgery ", Surgical endoscopy, 25(7), 2011, pp.2268-2274.

[15]M. Meißner, J. Pfeiffer, C. Peukert, H. Dietrich and T. Pfeiffer, "How virtual reality affects consumer choice", Journal of Business Research, 117, 2020, pp.219-231.

[16]K. Lee, and N. Chung, "Empirical analysis of consumer reaction to the virtual reality shopping mall", Computers in Human Behavior, 24, 2008, pp.88-104.

[17]C. Flavián, S. Ibáñez-Sánchez and C. Orús, "The impact of virtual, augmented and mixed reality technologies on the customer experience", Journal of Business Research, 100, 2019, pp.547-560.

[18]A.B. Craig, "Understanding augmented reality: Concepts and applications", Morgan Kaufmann, Waltham, MA, 2013.

[19]S. Maad, S. Garbaya and S. Bouakaz, "From virtual to augmented reality in financial trading: a CYBERII application", Journal of Enterprise Information Management, 21, 2008, pp.71-80.

[20]X. Fan, Z. Chai, N. Deng and X. Dong, "Adoption of augmented reality in online retailing and consumers' product 
attitude: A cognitive perspective", Journal of Retailing and Consumer Services, 53, 2020.

[21]E. Pantano, A. Rese and D.Baier, "Enhancing the online decision making process by using augmented reality : a two country comparison of youth markets", Journal of Retailing and Consumer Services, 38, 2017, pp. 81-95.

[22]M. Bujic, N. Xi and J. Hamari, "Emotional Response to Extended Realities: The Effects of Augmented and Virtual Technologies in a Shopping Context", 54th Annual Hawaii International Conference on System Sciences, 2021.

[23]M. Rovaglio, R. Calder, and P. Richmond, "Bridging the experience gap-How do we migrate skills and knowledge between the generations?", Computer Aided Chemical Engineering, 30, 2012, pp. 1407-1411.

[24]O. Svenson, W.R. Crozier and R. Ranyard, "Decision making : cognitive models and explanations", London ; New York : Routledge, 1997.

[25]R. Azuma, M. Daily and C. Furmanski, "A review of time critical decision making models and human cognitive processes",2006 IEEE Aerospace Conference, 2006, pp. 9.

[26]A. Stankevich, "Explaining the Consumer decision making Process: Critical Literature Review", Journal of International Business Research and Marketing, 2(6), 2017, pp. 7-14.

[27]J. Payne, J. R. Bettman and E. J. Johnson, "Consumer decision making. Handbook of Consumer Behaviour", 1991, pp. $50-84$

[28]M. Heitmann, D.R. Lehmann, D. R. and A. Herrmann, "Choice goal attainment and decision and consumption satisfaction", Journal of Marketing Research, 44(2), 2007, pp. 234-250.

[29]W. Edwards, "The theory of decision making", Psychological Bulletin, 51(4), 1954, pp. 380-417.

[30]C. W. Kirkwood, "Strategic decision making: Multiobjective Deci- sion Analysis with Spreadsheets", Duxbury Press, 1997.

[31]S. Basu and K. Savani, "Choosing one at a time? Presenting options simultaneously helps people make more optimal decisions than presenting options sequentially", Organizational Behavior and Human Decision Processes, 139, 2017, pp. 76-91.

[32]J. Banks, L. S. Carvalho, and F. Perez-Arce, "Education, decision making, and economic rationality", Review of Economics and Statistics, 101(3), 2019, pp. 428-441.

[33]S. Choi, S. Kariv, W. Müller, and D. Silverman, "Who is (more) rational?", American Economic Review, 104(6), 2014, pp. $1518-1550$

[34]S. Papagiannidis, E. Pantano, E. See-To E and M. Bourlakis, "Modelling the determinants of a simulated experience in a virtual retail store and users' product purchasing intentions", Journal of Marketing Management, 29:13-14, 2013, pp.1462-1492.

[35]P. Ballantine and D. Fortin, "The Effects of Interactivity and Product Information on Consumers' Emotional Responses to an Online Retail Setting", International Journal of Internet Marketing and Advertising, 5, 2009, pp. 260.
[36]T. Hennig-Thurau and A. Klee, "The impact of customer satisfaction and relationship quality on customer retention: A critical reassessment and model development", Psychology \& Marketing, 14, 1997, pp. 737-764.

[37]S. Papagiannidis, E. Pantano, E. See-To, C. Dennis and M. Bourlakis, "To immerse or not? Experimenting with two virtual retail environments", Information Technology and People, 30, 2017, pp. 163-188.

[38]H. Oh, S.Y. Yoon and C.R. Shyu, "How can virtual reality reshape furniture retailing?", Clothing and Textiles Research Journal, 26 (2), 2008, pp. 143-163.

[39]K. S. Suh, and Y. E. Lee, "The effects of virtual reality on consumer learning: an empirical investigation", MIS Quarterly, 29 (4), 2005, pp. 673-697.

[40]H. J. Kang, J. Shin, and K. Ponto, "How 3D Virtual Reality Stores Can Shape Consumer Purchase Decisions: The Roles of Informativeness and Playfulness", Journal of Interactive Marketing, 49, 2020, pp. 70-85.

[41]A. Poushneh, and A.Z. Vasquez-Parraga, "Discernible impact of augmented reality on retail customer's experience, satisfaction and willingness to buy", Journal of Retailing and Consumer Services, 34, 2017, pp. 229-234.

[42]Y. Lu and S. Smith, "Augmented Reality E-Commerce Assistant System: Trying While Shopping. In: Jacko J.A. (eds) Human-Computer Interaction. Interaction Platforms and Techniques", HCI 2007, Lecture Notes in Computer Science, vol 4551. Springer, Berlin, Heidelberg, 2007.

[43]A. S. Fotheringham, "Note-consumer store choice and choice set definition", Marketing Science, 7(3), 1988, pp. 299-310.

[44]D. Perry Hinton, P. R. Hinton, I. McMurray, and C. Brownlow, "SPSS Explained", Routledge.

[45]A. Deshpande and I. Kim, "The effects of augmented reality on improving spatial problem solving for object assembly", Advanced Engineering Informatics, 38, 2018, pp. 760-775.

[46]K. H. Kim and K. Y. Wohn, "Effects on productivity and safety of map and augmented reality navigation paradigms", IEICE Transactions on Information and Systems, 94(5), 2011, pp. 1051-1061.

[47]D. Ariely and D. Zakay, "A timely account of the role of duration in decision making", Acta Psychologica, 108, 2001, pp. 187-207.

[48]A. Diederich, "Decision making under conflict: Decision time as a measure of conflict strength", Psychonomic Bulletin \& Review, 10, 2003, pp. 167-176.

[49]M. Cabanac and M.C. Bonniot-Cabanac, "Decision making: rational or hedonic?", Behavioral and Brain Functions, 3(1), 2007, pp. 1-8.

[50]H. Van Kerrebroeck, M. Brengman, and K. Willems, "Escaping the crowd: An experimental study on the impact of a virtual reality experience in a shopping mall", Computers in Human Behavior, 77, 2017, pp. 437-450.

[51]S. Altarteer and V. Charissis. "Technology acceptance model for 3D Virtual Reality System in luxury brands online stores”, IEEE Access, 7, 2019, pp. 64053-64062. 